\title{
Early Procedural Pain Is Associated with Regionally-Specific Alterations in Thalamic Development in Preterm Neonates
}

\author{
Emma G. Duerden, ${ }^{1}$ Ruth E. Grunau, ${ }^{5,6}$ Ting Guo, ${ }^{1}$ 'Justin Foong, ${ }^{1}$ Alexander Pearson, ${ }^{1}$ Stephanie Au-Young, ${ }^{1}$ \\ Raphael Lavoie, ${ }^{3}$ M. Mallar Chakravarty, ${ }^{3,4}$ (C) Vann Chau, ${ }^{1,2}{ }^{-}$Anne Synnes, ${ }^{5,6}$ and Steven P. Miller ${ }^{1,2}$ \\ ${ }^{1}$ Department of Paediatrics, The Hospital for Sick Children, Toronto, Ontario M5G 1X8, Canada, ${ }^{2}$ The University of Toronto, Toronto, Ontario M5S 1A1, \\ Canada, ${ }^{3}$ Cerebral Imaging Centre, Douglas Mental Health University Institute, Montreal, Quebec H4H 1R3, Canada, ${ }^{4}$ Departments of Psychiatry and \\ Biomedical Engineering, McGill University, Montreal, Quebec H3A 2B4, Canada, ${ }^{5}$ Department of Pediatrics, University of British Columbia, Vancouver, \\ British Columbia V6H 3V4, Canada, and 'BC Children's and Women's Hospitals, BC Children's Hospital Research Institute, Vancouver, British Columbia \\ V6H 3N1, Canada
}

Very preterm human neonates are exposed to numerous invasive procedures as part of life-saving care. Evidence suggests that repetitive neonatal procedural pain precedes long-term alterations in brain development. However, to date the link between pain and brain development has limited temporal and anatomic specificity. We hypothesized that early exposure to painful stimuli during a period of rapid brain development, before pain modulatory systems reach maturity, will predict pronounced changes in thalamic development, and thereby cognitive and motor function. In a prospective cohort study, 155 very preterm neonates ( 82 males, 73 females) born $24-32$ weeks' gestation underwent two MRIs at median postmenstrual ages 32 and 40 weeks that included structural, metabolic, and diffusion imaging. Detailed day-by-day clinical data were collected. Cognitive and motor abilities were assessed at 3 years, corrected age. The association of early (skin breaks, birth-Scan 1 ) and late pain (skin breaks, Scans 1-2) with thalamic volumes and $N$-acetylaspartate (NAA)/choline (Cho), and fractional anisotropy of white-matter pathways was assessed. Early pain was associated with slower thalamic macrostructural growth, most pronounced in extremely premature neonates. Deformation-based morphometry analyses confirmed early pain-related volume losses were localized to somatosensory regions. In extremely preterm neonates early pain was associated with decreased thalamic NAA/Cho and microstructural alterations in thalamocortical pathways. Thalamic growth was in turn related to cognitive and motor outcomes. We observed regionally-specific alterations in the lateral thalamus and thalamocortical pathways in extremely preterm neonates exposed to more procedural pain. Findings suggest a sensitive period leading to lasting alterations in somatosensory-system development.

Key words: critical period; DTI; MRI; MRS; pain; preterm

Significance Statement

Early exposure to repetitive procedural pain in very preterm neonates may disrupt the development of regions involved in somatosensory processing, leading to poor functional outcomes. We demonstrate that early pain is associated with thalamic volume loss in the territory of the somatosensory thalamus and is accompanied by disruptions thalamic metabolic growth and thalamocortical pathway maturation, particularly in extremely preterm neonates. Thalamic growth was associated with cognitive and motor outcome at 3 years corrected age. Findings provide evidence for a developmentally sensitive period whereby subcortical structures in young neonates may be most vulnerable to procedural pain. Furthermore, results suggest that the thalamus may play a key role underlying the association between neonatal pain and poor neurodevelopmental outcomes in these high-risk neonates.

\section{Introduction}

Infancy is characterized by critical periods of experience-induced plasticity when the brain is adaptable to novel sensory informa-

Received March 27, 2017; revised Nov. 17, 2017; accepted Nov. 22, 2017

Author contributions: E.G.D., R.E.G., V.C., A.S., and S.P.M. designed research; E.G.D., R.E.G., V.C., A.S., and S.P.M. performed research; M.M.C. contributed unpublished reagents/analytic tools; E.G.D., T.G., J.F., A.P., S.A.-Y., R.L., M.M.C., and V.C. analyzed data; E.G.D. and S.P.M. wrote the paper. tion. Little research has focused on sensitive windows for nociceptive and somatosensory systems despite evidence suggesting neonatal tissue damage may have long-lasting effects on pain 


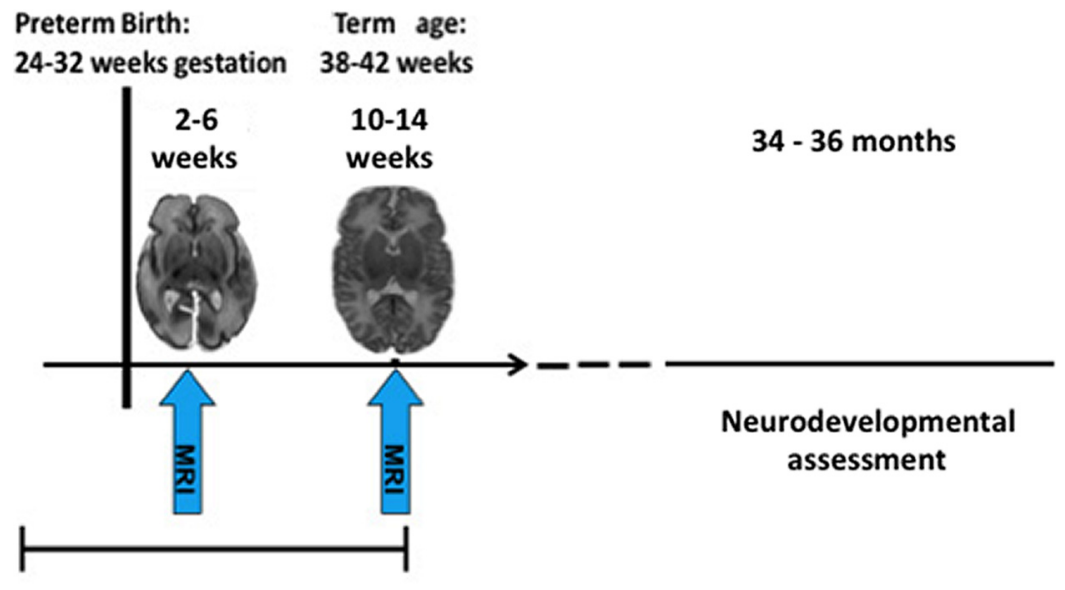

Daily measures of clinical care

Figure 1. Timeline of study procedures.

processing systems (R. V. Grunau et al., 1994a) and functional outcomes (R. E. Grunau et al., 2009; Brummelte et al., 2015). The thalamus is a relay for nociceptive pathways and developing thalamocortical projections may be disrupted by early pain.

Preterm-born neonates often undergo hundreds of invasive procedures during intensive care (Carbajal et al., 2008). Extremely preterm born neonates ( $\leq 28$ weeks' gestation) may be most susceptible to pain exposure, occurring at a time of rapid and vulnerable brain development (Back and Miller, 2014). Nociceptive systems become functional at 24-28 weeks' gestation with the development of thalamocortical connections (Andrews and Fitzgerald, 1994); however, brainstem-mediated endogenous pain modulation only develops closer to term-equivalent age (Fitzgerald, 2005). Thus, exposure to pain at earlier gestational ages may have differential effects on the developing brain.

Neonatal pain contributed to poorer cognitive and motor outcome at 18 months corrected age (CA; R. E. Grunau et al., 2009), and predicted IQ at school age (Vinall et al., 2014) in preterms. Pain in preterms precedes specific alterations in the frontal cortices and somatosensory system (Ranger et al., 2013) and somatosensory processing (R. V. Grunau et al., 1994a; Hermann et al., 2006; Goffaux et al., 2008; Walker et al., 2009). Neonatal pain may have lasting consequences on subcortical gray and white-matter development subserving somatosensory, cognitive, and motor processes.

Our earlier work suggests that neonatal intensive care unit (NICU)-related invasive procedures are associated with widespread alterations in thalamic metabolic development and whitematter microstructural pathways in very preterm born neonates (Brummelte et al., 2012). The long-term sequelae of early exposure to noxious stimuli in animals suggests that the first weeks of life may be a period of enhanced vulnerability, with susceptibility increasing with earlier exposure during development (Anand et al., 1999; Ren et al., 2004; Beggs et al., 2012). In the present study, our central hypothesis was that early skin breaks administered to

for database development; Dr. Kenneth Poskitt for scoring the MRI scans acquired in the neonates; Dr. Rollin Brant for review and comments on the statistical analyses; and Christopher Hammill for technical support for the deformation based morphometry analyses.

The authors declare no competing financial interests.

Correspondence should be addressed to Dr. Steven P. Miller, Hospital for Sick Children, 555 University Avenue, Toronto, 0N M5G 1X8, Canada. E-mail: steven.miller@sickkids.ca.

DOI:10.1523/JNEUROSCI.0867-17.2017

Copyright $\odot 2018$ the authors $\quad 0270-6474 / 18 / 380879-09 \$ 15.00 / 0$ extremely preterm neonates would be associated with regionally-specific alterations in thalamic and thalamocortical fiber pathway maturation. We used three complementary neuroimaging measures to examine congruence of findings across thalamic development: structure, metabolism, and microstructure in a group of extremely (24-28 weeks' gestation) and very (29-32 weeks' gestation) preterm born neonates who underwent MRI earlyin-life and at term-equivalent age.

To address our primary aim, models testing the association of early (birthScan 1) and late (Scans 1-2) invasive procedures accounted for repeated measures and were applied to the neuroimaging data. Given previous research suggesting an association among invasive procedures, brain development and poorer functional outcomes in preterm neonates, our secondary aim was to assess the association between thalamic development and two assessments of neurodevelopmental outcome: cognitive and motor function. To address our second aim, cognitive and motor abilities were assessed using the Bayley Scales of Infant and Toddler Development, third edition (Bayley-III) at 3 years CA in relation to thalamic growth.

\section{Materials and Methods}

Participants. One hundred fifty-five neonates ( 82 males and 73 females) admitted to the NICU at BC Women's Hospital, Canada, were enrolled in the study between 2006 and 2013. Birth at 24-32 weeks' gestation was the sole eligibility criterion. Neonates were excluded based on the following criteria: congenital malformations/syndromes, antenatal infections, or large $(>2 \mathrm{~cm})$ parenchymal hemorrhagic infarctions. Neonates with two scans and detailed daily clinical data were included in this study. The Clinical Research Ethics Board at the University of British Columbia and Children's and Women's Health approved the study. Written informed consent was obtained from parents or legal caregivers.

Magnetic resonance imaging. Neonates were scanned on a Siemens 1.5T Avanto MRI (VB 13A software) inside an MR-conditional incubator (Lammers Medical Technology) using a single-channel neonatal head coil (Advanced Imaging Research; Fig. 1). Neonates underwent their first MRI scan when clinically stable for transport (median postmenstrual age 32 weeks; IQR = 30.7-33.0) and again at term-equivalent age (median age 40 weeks; IQR $=38.7-42$ ). Anatomical imaging included the acquisition of T1-weighted [repetition time $(\mathrm{TR})=36$; echo time $(\mathrm{TE})=9.2$; field-of-view $(\mathrm{FOV})=192 \times 88 \mathrm{~mm}$; voxel size: $1.04 \times 1.00 \times 1.04 \mathrm{~mm}$; no gap] and T2-weighted images $(\mathrm{TR}=4610 ; \mathrm{TE}=107$; FOV $=20 \times$ $402 \mathrm{~mm}$; voxel size $=0.4 \times 0.4 \times 4.48 \mathrm{~mm}$; gap $=0.2 \mathrm{~mm})$. The magnetic resonance spectroscopic imaging (MRSI) data were acquired using multivoxel chemical shift imaging (TR: $1500 \mathrm{~ms}$; TE: 144; averaging 4). Diffusion tensor imaging (DTI) data were acquired using a multirepetition, single-shot echoplanar sequence $[\mathrm{TR}=4900, \mathrm{TE}=104$; motion-probing gradient in 12 diffusion-encoding directions with 3 averages of 2 diffusion weightings of 600 and $700 \mathrm{~s} / \mathrm{mm}^{2}$ ( $b$ value) and a non-diffusion-weighted image; FOV $=160 \mathrm{~mm} ; 1.3 \mathrm{~mm}$ in-plane resolution; slice thickness $=3 \mathrm{~mm}$ ].

Anatomical images were reviewed for the presence and severity of white matter injury (WMI). WMI was defined as foci exhibiting T1 hyperintensity without significant T2 hypointensity. WMI volumes were calculated through a manual segmentation protocol (Guo et al., 2017).

Volumetric measurements of the thalamus. Volumetric measurements of the thalamus were performed on the early-in-life and term-equivalent age scans using the T1-weighted images. A semiautomatic method previously described by Guo et al. (2015) was applied to the T1-weighted images ac- 
quired at the two time points. In brief, one of the authors (A.P.) manually segmented the left and right thalami on a selection of randomly chosen early and term T1-weighted images using the Display software package (en.wikibooks.org/wiki/MINC/VisualTools/Display). T1-weighted images were visualized and the thalamus was segmented in simultaneous coronal, sagittal, and axial views of the brain. Manual thalamic segmentations were used as templates for subsequent automatic thalamic segmentation of all T1-weighted images by using the Multiple Automatically Generated Templates (MAGeT) Brain (Chakravarty et al., 2013) pipeline. Using the pipeline, the manual segmentations of the thalamus were propagated to the T1-weighted images of the entire cohort permitting the volume calculation of the left and right thalami for each participant. The left and right values were averaged for each participant's thalamic volumetric measurements and were used in subsequent statistical models.

Deformation-based morphometry analysis. Regionally-specific alterations in thalamic volume were estimated using deformation-based morphometry (DBM; Ashburner et al., 1998). First, templates for the early-in-life and term-equivalent age scans were created using the T1weighted images. Templates were created by developing an average of all T1-weighted images collected at the two time points. T1-weighted images were nonlinearly coregistered using Advanced Normalization Tools (Avants et al., 2008, 2011). Each individual T1-weighted image was aligned to the early-in-life or term-equivalent age templates depending on the age of the neonates at scan using affine transformations. A nonlinear registration algorithm was then used for precise alignment of the native T1-weighted images to the template images. The final registrations create the Jacobian determinants of the deformation fields describing the shape differences in expansion and contraction at each voxel in the template MRI. Log-transformed Jacobian determinants were used in the final statistical analyses as they are more representative of the normal distribution.

MRSI. The MRSI data were analyzed using a region-of-interest approach by one of the authors (V.C.). A volume-of-interest (VOI; $50 \times 50 \times$ $10 \mathrm{~mm}$ thick) was selected at the level of the basal nuclei. Within the VOI, the peak-area spectra were analyzed in the thalamus using Siemens' MRS processing software. Voxels with adequate signal-to-noise ratio and that were fully included in the VOI were used for statistical analyses as described previously (Chau et al., 2009; Brummelte et al., 2012). The mean $\mathrm{N}$-acetylaspartate (NAA)/choline (Cho) and lactate/Cho ratios for each ROI were calculated bilaterally; these methods have high intra-rater reliability (Brummelte et al., 2012).

DTI analysis. Diffusion-weighted images were processed using the FMRIB software library (http://www.fmrib.ox.ac.uk/fsl/; Jenkinson et al., 2012). Data were corrected for eddy-current effects. Each participants' diffusion-weighted volumes were registered to a single nondiffusion-weighted volume using affine transformations (Jenkinson and Smith, 2001; Jenkinson et al., 2002). The estimated diffusion tensor data were masked using the Brain Extraction Tool (Jenkinson et al., 2002) to include only brain tissue. A diffusion tensor model was fit to the data at each voxel and to calculate voxelwise fractional anisotropy (FA) values. To better determine the spatial location of alterations in FA values in the neonatal brain, volumes were processed using the Tract-based spatial statistics (TBSS) pipeline (Smith et al., 2006). FA images were nonlinearly aligned (Avants et al., 2008, 2011) to age-appropriate templates as previously described (Duerden et al., 2015) to calculate voxelwise statistics. Last, the Johns Hopkins University (JHU) atlas was nonlinearly registered to the age-based templates and the FA values from the corpus callosum, posterior white matter (posterior corona radiata, posterior thalamic radiation), internal capsule (anterior, posterior limbs, corticospinal tract), and cingulum (cingulum, fornix) from the left and right sides were averaged leaving a total of four ROIs. The FA data were extracted and used for statistical modeling.

Clinical data collection. Clinical data were systematically collected from the infants' NICU charts by a neonatal nurse and a pediatric neurologist. As a measure of pain each individual invasive procedure involving skin breaks was prospectively documented by nursing staff, including but not limited to heel lances, intubations, intravenous or central line insertion, and intramuscular injection (described by R. E. Grunau et al., 2009;
Brummelte et al., 2012). Each attempt at an invasive procedure was counted daily. Cumulative doses of midazolam, morphine, and dexamethasone in milligrams were calculated (intravenous dose plus converted oral dose) as the average daily dose adjusted for daily body weight. Other clinical variables included: gestational age (GA) at birth, biological sex, days of life (DOL) at scan, postmenstrual age (PMA) at scan, morphine dose, midazolam dose, dexamethasone dose, and days of mechanical ventilation.

Neurodevelopmental outcomes at 3 years. Toddlers and their families returned for neurodevelopmental follow-up at the clinic at BC Women's Hospital at 3 years of age corrected for prematurity (CA). Neurodevelopmental abilities were assessed using the Bayley-III, which yields cognitive and motor composite scores ( mean $=100 ; \mathrm{SD}=15$ ).

Statistical analysis. The Statistical Package for the Social Sciences (v24, SPSS) was used for the volumetric, microstructural and brain metabolite statistical analyses. The DBM analyses were performed using the R statistical software package.

To investigate the association of early and late invasive procedures on thalamic macrostructural and metabolic growth, as well as the microstructural development of thalamocortical pathways, the thalamic volumes, NAA/Cho, and FA values from the early in life and term-equivalent age scans were modeled in three separate analyses [(1) volumes, (2) NAA/ Cho, (3) FA)] using generalized estimating equations to account for repeated measures. Early invasive procedures included the total number of skin breaks recorded from birth until the time of the first scan, whereas the late invasive procedures included the total number of skin breaks from the time immediately after the first scan until the second scan. Invasive procedures were entered into the analysis as categorical or continuous variables. For categorical variables, the median number of skinbreaking procedures from birth to Scan 1 (low early skin breaks: <49; high early skin breaks: $>50$ ) and from Scan 1 to Scan 2 (low late skin breaks: $<31$; high early skin breaks: $>32$ ) were used to divide the cohort. Variables known to influence brain development were entered as covariates and included: DOL at MRI, GA at birth (weeks), biological sex, total morphine, midazolam and dexamethasone doses $(\mathrm{mg})$, days of intubation, and total cerebral volumes (volumetric analyses only). The variables of DOL at MRI and GA at birth were used to account for the PMA at scan in the regression analyses. We conducted an exploratory analysis in which we visualized the standardized residuals of the model and created scatterplots of the residuals to assess their distribution. If the final models assessing macrostructural growth were significant and the residuals were homoscedastic, then models were repeated to examine the effects of early and late skin breaks on thalamic metabolic maturation in the extremely preterm neonates compared with neonates born very preterm. If the final model was significant in the extremely preterm population, then the models were repeated to examine the association of early and late skin breaks with thalamic metabolic development and microstructural development of thalamocortical pathways in neonates born $\geq 29$ weeks' gestation, adjusting for factors related to prematurity and illness severity. As we had one a priori central hypothesis regarding the association of early skin breaks in the extremely preterm neonate with thalamic maturation, the $\alpha$ level for statistical tests for the volumetric and metabolic data were set to 0.05 .

Neurodevelopmental outcome scores (cognitive and motor) were assessed in relation to the weekly growth of the thalamus (thalamic volume Scan 2 - thalamic volume Scan 1/PMA at Scan 2 - PMA at Scan 1), adjusting for GA at birth and biological sex. For our secondary aim regarding thalamic development and neurodevelopmental outcome, we had two hypotheses in relation to cognitive and motor outcomes and the $\alpha$ level was set at 0.025 .

For the DBM analyses, the association of early and late skin breaks were assessed in relation to the log-transformed Jacobians developed from the first and second scan data using two separate linear regression models (early skin breaks and Scan 1, late skin breaks and Scan 2), adjusting for the ages at scan, using the RMINC toolkit with the R statistical software package (http://www.R-project.org/). $t$ Tests at each voxel assessed the significance of the regression models. As the primary area of interest was the thalamus, a thalamic mask was applied to the data. Masked data were corrected for multiple comparisons using the false 
Table 1. Characteristics for the full cohort $(N=155)$ and comparisons of demographic information for neonates born before or after 28 weeks

\begin{tabular}{|c|c|c|c|}
\hline Characteristic & $\begin{array}{l}\text { Total } \\
N=155\end{array}$ & $\begin{array}{l}\text { Birth GA } 24-28 \text { weeks } \\
n=94\end{array}$ & $\begin{array}{l}\text { Birth GA } 29-32 \text { weeks } \\
n=61\end{array}$ \\
\hline Birth GA & $27.6(25.9-29.9)$ & $26.3(25.4-27.3)$ & $30.1(29.6-31.4)$ \\
\hline \multicolumn{4}{|l|}{ Median weeks (IQR) } \\
\hline Male, no. (\%) & $82(53)$ & $49(52)$ & $33(54)$ \\
\hline PMA MRI 1, median (IQR) & $32.3(30.7-33.7)$ & $32(30-35)$ & $32.3(31.4-33.43)$ \\
\hline PMA MRI 2, median (IQR) & $40.3(39-42)$ & $40.3(39-42)$ & $40.3(39.3-43)$ \\
\hline DOL MRI 1, median (IQR) & $21(12-46)$ & $38(20-60)$ & $12(8-17)$ \\
\hline DOL MRI 2, median (IQR) & $90.5(70-101)$ & $97(89-105)$ & $69(60-84)$ \\
\hline Days of mechanical ventilation, median (IQR) & $4(1-27)$ & $16.5(0-121)$ & $1(0-2)$ \\
\hline Fentanyl, median dose ${ }^{a}(\mathrm{IQR}) ;$ no. exposed & $0.007(0.005-0.022) ; 34$ & $0.008(0.005-0.02) ; 31$ & $0.003(0.003-0.006) ; 3$ \\
\hline Morphine, median dose ${ }^{a}(\mathrm{IQR})$; no. exposed & $1.8(0.18-7.9) ; 96$ & $2.85(0.4-13.7) ; 74$ & $0.15(0.13-1.5) ; 22$ \\
\hline Midazolam, median dose ${ }^{a}(\mathrm{IQR})$; no. exposed & $6.8(4.3-12.7) ; 29$ & $7.1(4.1-12.8) ; 28$ & $0(0) ; 1$ \\
\hline Dexamethasone, median dose ${ }^{a}(\mathrm{IQR}) ;$ no. exposed & $1.2(0.75-2.4) ; 28$ & $1.2(0.75-2.4) ; 28$ & $0(0) ; 0$ \\
\hline Total skin breaks, median (IQR) & $101(65-168)$ & $142(97-208)$ & $58(46-74)$ \\
\hline Early skin breaks, median (IQR) & $49(30-185)$ & $84(42-158)$ & $34(23-45)$ \\
\hline Late skin breaks, median (IQR) & $31(18-57)$ & $44(25-66)$ & $24(13-31)$ \\
\hline
\end{tabular}

Probability values provide results using $t$ tests for continuous measures and $\chi^{2}$ tests for categorical measures comparing neonates born extremely (24-28 weeks' gestation) and very preterm ( $29-32$ weeks' gestation). ${ }^{a}$ Cumulative dose in milligrams adjusted for daily body weight.

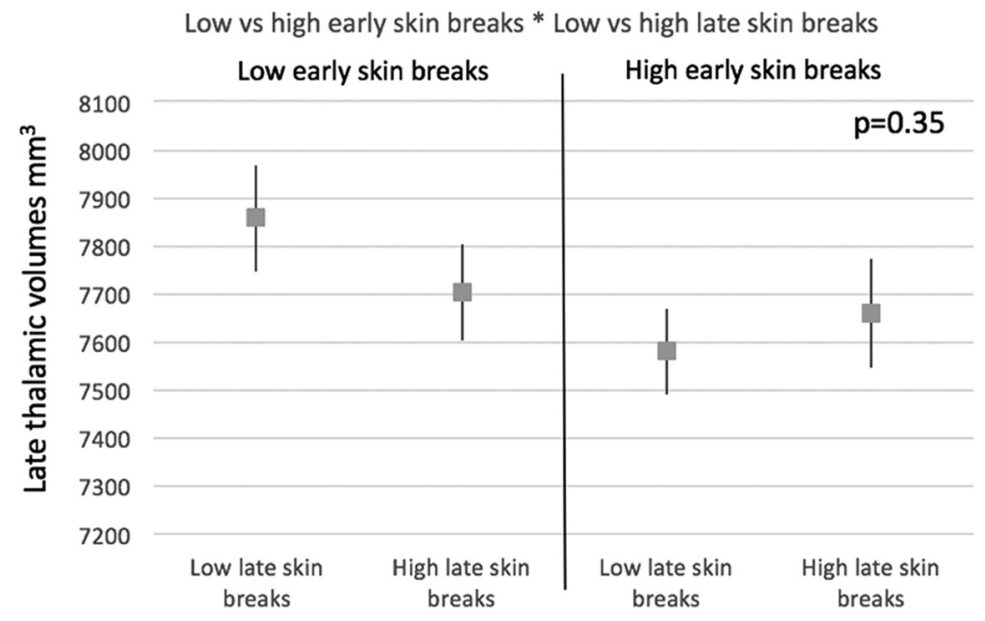

Figure 2. Late skin-breaking procedures were not significantly associated with variations in thalamic volumetric development at term equivalent age and were not dependent on neonates' prior exposure to early skin-breaking procedures $(p=0.35)$. Estimated marginal means of thalamic volumes adjusting for male sex, GA at birth, DOL at scan, days of intubation, morphine dose, midazolam dose, dexamethasone dose, and total cerebral volume. Error bars are the SE of the estimated marginal means.

discovery rate (Genovese et al., 2002). A $p$ value of 0.05 was considered statistically significant.

For the DTI analysis, as we had four ROIs in the white matter, we corrected for the total number of comparisons and the $\alpha$ level was set at 0.013 .

\section{Results}

Clinical characteristics and diagnostic MRI findings

One hundred fifty-five preterm neonates participated in the study [53\% boys; median birth gestational age (GA): 27.6 weeks; interquartile range (IQR): 25.9-29.9; Table 1]. Of these neonates, 94 (61\%) were born extremely preterm (24-28 weeks' gestation; $52 \%$ boys; median birth GA: 26.3 weeks; IQR: 25.4-27.3) and 61 (39\%) were born very preterm (29-32 weeks' gestation; 54\% boys; median birth GA: 30.1 weeks; IQR: 29.6-31.4). As expected, extremely preterm born neonates had a longer NICU stay before the first scan, were on a ventilator for more days, had greater total doses of morphine, midazolam, and dexamethasone compared with neonates born 29-32 weeks' gestation. Extremely preterm born neonates did not exhibit significantly greater volume of WMI ( $\beta=463.6, p=0.16)$ measured by manual segmen- tation compared with their counterparts born at 29-32 weeks' gestation, adjusting for birth GA, DOL at scan, and total cerebral volume. The WMI volume did not significantly differ between neonates that received a high or low number of early invasive procedures $(\beta=40.4, p=0.7)$, adjusting for the same demographic and clinical care factors noted above.

\section{Early skin breaks are associated with slower thalamic macrostructural growth}

Higher early skin-breaking procedures (>median 50 skin breaks), when used as a categorical variable, demonstrated slower thalamic growth across both scans $(\beta=$ $-194.6, p=0.04$ ), adjusting for DOL at MRI, GA at birth (weeks), biological sex, total morphine, midazolam, and dexamethasone doses $(\mathrm{mg})$, days of intubation, and total cerebral volumes. In comparison, higher later acquired skinbreaking procedures ( $>32$ skin breaks) did not predict thalamic volume compared with those that received a low number of skin-breaking procedures in the late neonatal period $(\beta=-3.5, p=0.96)$. Furthermore, late skinbreaking procedures were not associated with differences in thalamic volume at term regardless of whether neonates had received low or high numbers of early skin-breaking procedures (Fig. 2; Table 2).

The model was repeated examining the association of early and late skin breaks with thalamic growth during the neonatal period in groups of neonates born before or after 28 weeks' gestation. Extremely preterm born neonates exposed early to higher numbers of skin-breaking procedures showed a significant decrease in thalamic growth $(p=0.04$; Table 3 ; Fig. $3 a)$, but thalamic volume was not associated with later pain $(p=0.9)$, adjusting for sex, birth GA, DOL at scan, total morphine dose, midazolam dose, dexamethasone dose, days of mechanical ventilation, and total cerebral volume. In contrast with extremely preterm born neonates, thalamic growth in very preterm born neonates (29-32 weeks' gestation) was not associated with early 
Table 2. Results of a generalized estimating equation for late thalamic volumes $(S c a n 2)$ describing the interaction between early $\times$ late skin-breaking procedures

\begin{tabular}{lcc}
\hline & $\beta$ values & $p$ values \\
\hline Male sex & 100.7 & 0.27 \\
Birth GA & 73.2 & 0.06 \\
DOL at MRI & 12.2 & $<0.001^{a}$ \\
Morphine dose & 2.9 & 0.37 \\
Midazolam dose & 2.0 & 0.85 \\
Dexamethasone dose & -5.9 & 0.93 \\
Days of intubation & -5.0 & 0.16 \\
Early pain X late pain & 197.6 & 0.35 \\
$\quad$ Low early skin breaks * low late skin breaks & 43.5 & 0.29 \\
Low early skin breaks * high late skin breaks & -78.9 & 0.78 \\
High early skin breaks * low late skin breaks & & 0.55 \\
High early skin breaks * high late skin breaks ${ }^{b}$ & - & -0.01 \\
Total cerebral volume & & $<0.001^{a}$ \\
\hline Estimated coefficients and $p$ values for the interaction of early (low/high) by late (low/high) skin-breaking \\
procedures. & & \\
${ }^{a}$ Statistically significant, $p<0.05$. & & \\
${ }^{b}$ Comparison group. & &
\end{tabular}

Table 3. Results of linear regression models for thalamic volumes relative to early skin breaks

\begin{tabular}{lrllcll}
\hline & \multicolumn{2}{l}{$\begin{array}{l}24-28 \text { weeks }^{\prime} \\
\text { gestation }\end{array}$} & & \multicolumn{2}{l}{$\begin{array}{l}\text { 29-32 weeks' } \\
\text { gestation }\end{array}$} \\
\cline { 2 - 3 } \cline { 5 - 6 } & $\beta$ values & $p$ values & & $\beta$ values & $p$ values \\
\hline Male sex & 7.6 & 0.93 & & -12.6 & 0.89 \\
Birth GA & 96.4 & 0.2 & & 137.4 & $0.02^{a}$ \\
DOL at scan & 23.3 & $0.02^{a}$ & & 10.3 & $0.037^{a}$ \\
Morphine dose & 1.7 & 0.33 & & 104.66 & $0.002^{a}$ \\
Midazolam dose & -4.2 & 0.47 & & -806.79 & $0.029^{a}$ \\
Dexamethasone dose & -63.3 & 0.21 & & - & - \\
Days of mechanical ventilation & -3.13 & 0.37 & & -100.07 & $0.0001^{a}$ \\
High early skin breaks & -211.81 & $0.04^{a}$ & & -20.45 & 0.85 \\
High late skin breaks & 9.44 & 0.93 & & 133.46 & 0.21 \\
TCV & 0.01 & $0.0001^{a}$ & & 0.02 & $0.0001^{a}$ \\
\hline
\end{tabular}

Estimated coefficients and $p$ values for early skin-breaking procedures in relation to thalamic volumes in extremely (24-28 weeks' gestation) and very preterm (29-32 weeks' gestation) neonates. TCV, Total cerebral volume. ${ }^{a}$ Statistically significant, $p<0.05$.

$(\beta=-20.45, p=0.85)$ or late skin breaks $(\beta=133.46, p=0.2)$, controlling for the above clinical factors.

\section{Early skin breaks are associated with reduced volume in the lateral thalamus}

To determine the spatial localization of the volumetric changes in the thalamus the T1-weighted images were subjected to DBM analyses to better understand relative change in volume on a voxelwise level. Early skin-breaking procedures were entered into a linear model as continuous variables against the log-transformed Jacobian determinants describing the changes in shape relative to the average models for the early-in-life and term-equivalent age scans, adjusting for PMA at scan.

Early skin-breaking procedures were found to be significantly associated with a reduction in volume in the territory of the lateral thalamus $\left(t_{(152)}=-5.9, p<0.001\right.$, corrected $)$ in the early-life scans, which contains the somatosensory relay nuclei. Those neonates receiving $>100$ skin breaks in the early neonatal period exhibited a $4-6 \%$ relative decrease in volume in the lateral thalamus (Fig. 4).

Early skin breaks and reduced thalamic metabolites (NAA/Cho)

Early and late skin breaks in the neonatal period were assessed as categorical variables in relation to NAA values extracted from the thalamus relative to the reference metabolite Cho in neonates born extremely and very preterm in two separate models. In agreement with the volumetric findings, in the neonates born extremely preterm early skin breaks were associated with slower metabolic growth ( $p<0.0001$; Table 4; Fig. $3 b)$, adjusting for sex, birth GA, DOL at scan, total morphine dose, midazolam dose, dexamethasone dose; and days of mechanical ventilation. Later pain was not associated with NAA/Cho values $(p=0.5)$ in extremely preterm born neonates.

\section{Early skin-breaking procedures are associated with white matter microstructure}

Early and late skin-breaking procedures were first assessed as continuous variables in relation to FA values obtained from four white matter ROIs including the corpus callosum, posterior white matter, the internal capsule, and cingulum in the JHU neonatal atlas, adjusting for clinical variables in extremely preterm born neonates.

In the extremely preterm born cohort, early skin-breaking procedures were associated with FA in the corpus callosum $(p<$ 0.0001; Table 4; Fig. 3), posterior white matter comprised of the posterior corona radiata and posterior thalamic radiations $(p=$ $0.005)$, and the cingulum and fornix $(p=0.01)$. Late skinbreaking procedures were not found to be significantly associated with FA values in any of the assessed white-matter fiber pathways (corpus callosum: $\beta=0.00001, p=0.9$; posterior white matter: $\beta=0, p=0.4$; cingulum and fornix: $\beta=0.00001, p=0.9)$.

\section{Neurodevelopmental outcome at 3 years}

The majority of the children ( $n=122,79 \%$ of survivors) returned for assessments at 33-36 months corrected age (median age: 34.7 months; IQR: 33.7-36.1). The median scores for cognitive (100; IQR: 95-110) and motor (103; IQR: 94-110) outcomes were in the normal range.

\section{Relationship between neurodevelopmental outcome at 3 years and macrostructural thalamic growth}

Bayley-III outcome scores were assessed in two separate linear regression models as dependent variables in relation to the predictor variable weekly thalamic macrostructural growth (volume Scan 2 - volume Scan 1/age Scan 2 - age Scan 1), adjusting for birth GA and sex. In linear regression models, cognitive $(\beta=0.04$, $p=0.003)$ and motor scores $(\beta=0.06, p=0.0001)$ were predicted by thalamic volumetric growth adjusting for sex and GA at birth.

\section{Discussion}

Exposure to painful stimuli early in the neonatal period is independently associated with adverse alterations in thalamic macrostructural and metabolic growth. Alterations in macrostructural, metabolic, and microstructural growth were most pronounced in neonates born $<28$ weeks' gestation. Extremely preterm born neonates may represent a vulnerable group whereby painful lifesaving procedures may have long-term adverse effects on somatosensory system development.

Early but not later pain was associated with thalamic macrostructural, metabolic, and microstructural alterations as well as thalamocortical pathways and commissural and association white matter fibers. Our findings indicate some regional specificity in the thalamus for exposure to invasive procedures, compared with the hippocampus that showed no association with procedural pain after accounting for benzodiazepine exposure in this cohort (Duerden et al., 2016). Crucially, changes were most 


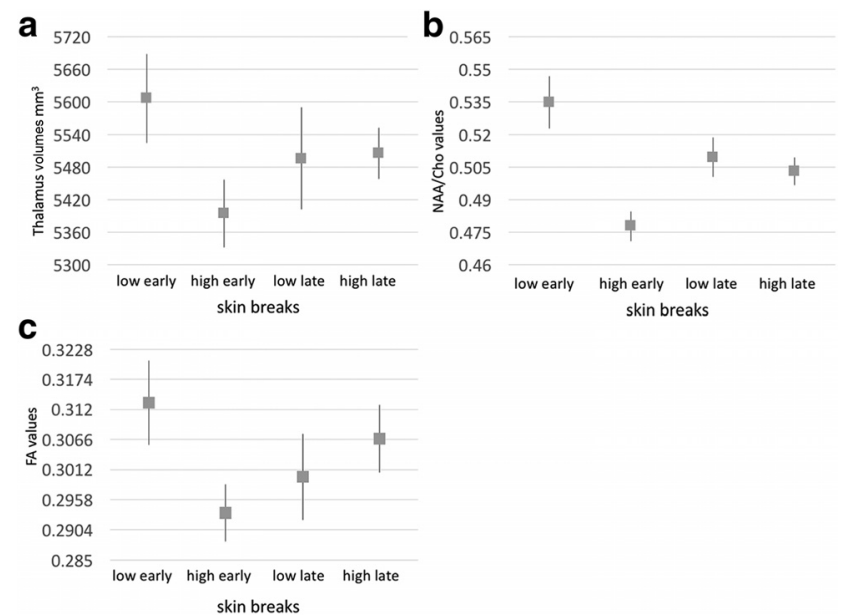

Figure 3. Extremely preterm neonates exposed to high early skin breaks demonstrate slower $(\boldsymbol{a})$ macrostructural $(\beta=$ $-211.81, p=0.04)$ and $(\boldsymbol{b})$ metabolic thalamic growth $(\beta=-0.06, p<0.0001)$ and $(\boldsymbol{c})$ microstructural development of posterior white matter $(\beta=-0.02, p=0.02)$ across early and term-equivalent age scans. Late skin breaks were not associated with delays in macrostructural $(\beta=9.4, p=0.9)$, metabolic $(\beta=-0.006, p=0.5)$, and microstructural development $(\beta=$ $0.007, p=0.5)$. Boxes represent the estimated marginal means of high/low early/late skin breaks fixed at the values for sex, birth GA, DOL at scan, total morphine dose, midazolam dose, dexamethasone dose, days of mechanical ventilation, and total cerebral volume (volume analysis only) in three separate models. Error bars are the SE of the estimated marginal means.

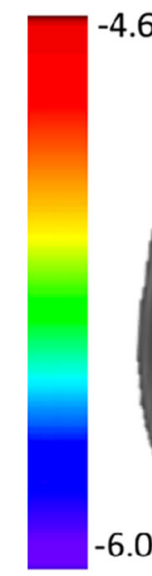

T values $p<0.001$

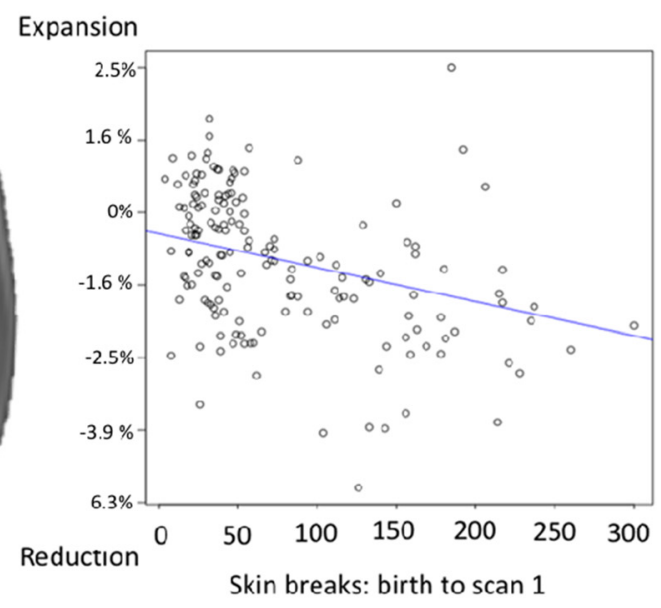

Figure 4. Volume loss in the lateral thalamus is associated with a greater number of early skin-breaking procedures $\left(t_{(152)}=\right.$ $-5.9, p<0.001$, corrected). Left, DBM $t$-statistic map overlaid on a template MRI developed from the T1-weighted images collected at the early-in life time point (median PMA: 32 weeks). $t$ Values reflect regional reductions in volume associated with the number of early skin-breaking procedures (birth-Scan 1). Right, Scatterplot of the relative increase and decrease values associated with early skin breaking procedures (birth-Scan1).

evident in neonates born extremely preterm. Animal studies reported age-sensitive periods in relation to the exposure of painful stimuli early in development (Anand et al., 1999; Ruda et al., 2000; Knaepen et al., 2013). Behavioral signs of enhanced sensitivity to painful stimuli at the site of injury are evident long-term in adult rats (Ren et al., 2004); however, early injuries are also accompanied by widespread alterations in basal thresholds at painnaive sites reflected in hyposensitivity to somatosensory and noxious stimuli. Altered sensitivity to painful stimuli will not occur in neonatal rat pups if inflammation or tissue damage is applied after the first weeks of life suggesting that young neonates are more vulnerable to the adverse effect of pain. Milder injuries are associated with more general hyposensitivity to painful stimuli later in adulthood (Ren et al., 2004; Sternberg et al., 2005; Laprairie and Murphy, 2009). The anatomic localization of the most prominent changes within the lateral thalamus is consistent with these experimental observations.

Early pain may act through several mechanisms resulting in hypersensitivity or hyposensitivity to noxious stimuli (Ren et al., 2004). Of note is that early life injury will result in developmentally-regulated effects on nociceptive pathways, not occurring at older ages in response to the same injury (Fitzgerald and Walker, 2009). Neonatal injury will result in hyperinnervation in the periphery (Reynolds and Fitzgerald, 1995; Moss et al., 2005) and will increase the receptive field sizes of dorsal horn neurons (Torsney and Fitzgerald, 2003). Also originating from the dorsal horn are neurons expressing the neurokinin 1 (NK1) receptor that project to pain modulatory systems in the brainstem. Dorsal horn neurons expressing the NK1 receptor terminate in brainstem pain modulatory systems and early pain may lead to increased opioid tone resulting in a decrease in pain sensitivity. Moreover, brainstem-mediated pain modulation exhibits age-sensitive periods (Fitzgerald and Koltzenburg, 1986; Hathway et al., 2009), where painful stimulation is facilitatory during the first weeks of postnatal development that becomes inhibitory later on in development. Additional mechanisms include the activation of the hypothalamicpituitary-adrenal (HPA) axis causing the release of cortisol and sensitizing dorsal horn neurons in the spinal cord. Sensitization of dorsal horn neurons may be an underlying cause of central sensitization resulting in alterations in the neuronal function of nociceptive pathways and thalamus. The HPA axis does not mature until late childhood (McCormick and Mathews, 2010; Foilb et al., 2011). Yet, pain in the preterm neonate is associated with an altered stress response through childhood (R. E. Grunau et al., 2013). Additionally, the activation of immune system modulators will release inflammatory molecules that sensitize fibers in the periphery (Schwaller and Fitzgerald, 2014; Zouikr et al., 2016), consistent with our finding that inflammatory factors were implicated in altered cortisol levels at school-age in very preterm children (R. E. Grunau et al., 2013).

During the development of the mammalian brain, afferent thalamocortical projections and their refinement into a topographic organization occurs through an activity-dependent manner (Shatz, 1990; Goodman and Shatz, 1993). During this process, axons from the thalamus contend for representation in the cortex. Should activity in this pathway be disrupted, the thalamocortical projections will be abnormally distributed. In the somatosensory system, projections from the ventral posterior nucleus of the thalamus to the primary somatosensory cortex are regulated by NMDA-dependent mechanisms (Crair and Malenka, 1995). Ad- 
Table 4. Results of linear regression models for thalamic NAA/Cho and FA values from white-matter fibre pathways relative to early skin breaks in neonates born extremely preterm

\begin{tabular}{|c|c|c|c|c|c|c|c|c|}
\hline & \multirow{2}{*}{\multicolumn{2}{|c|}{$\begin{array}{l}\text { NAA/Cho values } \\
\text { Thalamus }\end{array}$}} & \multicolumn{6}{|c|}{ FA values } \\
\hline & & & \multicolumn{2}{|c|}{ Corpus callosum } & \multicolumn{2}{|c|}{ Posterior white matter } & \multicolumn{2}{|c|}{ Cingulum + fornix } \\
\hline & $\beta$ values & $p$ values & $\beta$ values & $p$ values & $\beta$ values & $p$ values & $\beta$ values & $p$ values \\
\hline Male sex & -0.012 & 0.262 & -0.038 & $0.001^{b}$ & -0.041 & $<0.0001^{b}$ & -0.025 & 0.002 \\
\hline Birth GA & 0.021 & $<0.0001^{a}$ & 0 & 0.95 & -0.005 & 0.392 & -0.006 & 0.188 \\
\hline DOL at scan & 0.003 & $<0.0001^{a}$ & 0.001 & $<0.0001^{b}$ & 0.001 & $<0.0001^{b}$ & 0 & 0.202 \\
\hline Morphine dose & 0 & 0.414 & 0 & $0.17^{b}$ & -0.0001 & 0.678 & 0 & 0.008 \\
\hline Midazolam dose & -0.001 & 0.408 & -0.0001 & 0.89 & 0.0001 & 0.889 & -0.001 & 0.299 \\
\hline Dexamethasone dose & -0.007 & 0.121 & 0.015 & 0.89 & 0.01 & 0.02 & 0.01 & 0.015 \\
\hline Days of mechanical ventilation & 0 & 0.389 & -0.001 & $0.006^{\mathrm{b}}$ & -0.001 & $0.002^{b}$ & 0.011 & 0.12 \\
\hline High early skin breaks & -0.057 & $<0.0001^{a}$ & 0 & $<0.0001^{b}$ & 0 & $0.005^{b}$ & 0 & $0.01^{b}$ \\
\hline High late skin breaks & -0.006 & 0.546 & 0.00001 & 0.937 & 0 & 0.408 & 0.00001 & 0.876 \\
\hline
\end{tabular}

Estimated coefficients and $p$ values for early skin-breaking procedures in relation to NAA/Cho (left) values and FA (right) values in extremely (24-28 weeks' gestation) preterm neonates.

aStatistically significant, $p<0.05$.

${ }^{b}$ Statistically significant, $p<0.013 \mathrm{e}$

ditionally the NMDA-dependent mechanisms are only active early on in development and with age the ability to modify thalamocortical pathways fades (Crair and Malenka, 1995). Thus, these data indicate that activity in thalamocortical pathways is crucial for typical brain development. Early pain may therefore disrupt thalamocortical pathway development and underlie adverse cognitive and motor outcomes. Previous research has demonstrated regionally-specific alterations in white-matter fiber pathway maturation, including corpus callosum volume (Malavolti et al., 2017) and DTI measures of white matter microstructural development (Krishnan et al., 2007; Boardman et al., 2010; Chau et al., 2013; Duerden et al., 2015), and an association with adverse cognitive and motor outcome in the very preterm born population. In conjunction with the current findings, alterations in both thalamic maturation and thalamocortical projections appear to be key predictors of neurodevelopmental outcome in preterm born infants. Our findings also extend these observations made at 18 months of to 2 years age with neurodevelopmental outcomes assessments at 3 years of age.

Few studies have examined the association between alterations in gray matter and neonatal pain during the neonatal period (Smith et al., 2011; Brummelte et al., 2012). However, one study examined functional and structural cortical changes in a group of neonates exposed to NICU-related stress (Smith et al., 2011). Neonatal stress was associated with decreased brain width particularly impacting frontal and parietal lobes in preterms when assessed at term-equivalent age with structural MRI (Smith et al., 2011). In adults, painful dystonia was associated with regionallyspecific alterations in lateral thalamic nuclei reflected in 5-7\% decrease in volume (Südmeyer et al., 2012).

Long term follow-up studies of preterm-born children exposed to pain have examined pain reactivity and the association between exposure to noxious stimuli and brain morphometry. We found that extremely preterm low-birthweight neonates were reported as less reactive to painful stimuli based on parent report (R. V. Grunau et al., 1994b). Extremely preterm born children had a reduced ability to modulate pain compared with preterm children born at later gestational ages (Goffaux et al., 2008). Early exposure to tissue damage in the neonatal period may result in long-term structural plasticity in somatosensory and/or pain modulatory systems. Early skin breaks during the development of nociceptive and somatosensory systems may represent a mechanism by which preterm-born adults are predisposed to develop complex chronic pain conditions (Buskila et al., 2003; Kling- mann et al., 2008; Low and Schweinhardt, 2012). Together with our findings of altered neonatal thalamic development, these data suggest that early pain is associated with long-term alterations in somatosensory processing and somatosensory system development.

A challenge for clinical studies examining the association between neonatal pain and brain development is the difficulty of distinguishing between direct effects of exposure to painful stimuli and the confounding clinical variables. Previous neuroimaging findings with the preterm population have identified associations among clinical care factors and regionally-specific alterations in brain development (Tam et al., 2011; Duerden et al., 2016; Zwicker et al., 2016). Our findings suggest an association between early invasive procedures and altered development of the thalamus and thalamocortical pathways particularly in extremely preterm neonates. In our analyses, we adjusted for demographic and clinical factors, including the age of the participants at the time of birth and scan reflecting a lengthier stay in the NICU, which may have influenced the development of the thalamus. After adjusting for these factors, the association of early pain and thalamic development was maintained. Clinical care factors can have significant impact on neonatal brain development, for instance preterm neonates exposed antenatally to steroids demonstrated a $10 \%$ decrease in volume of the cerebellum (Tam et al., 2011). Our results do not provide a causal link between early pain and brain development, however, this has been demonstrated in a controlled neonatal animal experiment (Anand et al., 2007). Rather our clinical findings suggest an association between pain and brain development that is consistent with experimental work and that should be replicated in future cohorts of preterm born neonates. Strengths of the current study included multimodal neuroimaging assessments at two time points, detailed day-by-day neonatal clinical data collection, and neurodevelopmental assessments in a rare cohort of extremely preterm and very preterm born neonates studied from birth until the third year of life.

Neonates treated in intensive care undergo life-saving invasive procedures. Those who participated in the study were all exposed to early and late invasive procedures making it challenging to examine thalamic growth in subsets of neonates who were not exposed to any early pain relative to neonates having received a high number of early invasive procedures. Therefore, defining a critical period when the thalamus may be most vulnerable to invasive procedures during development would be imprecise based on the results of this study; instead our findings suggest a window of enhanced vulnerability. 
Our findings suggest a pathway by which early exposure to pain contributes to the neurodevelopmental consequence of extremely preterm birth. Future follow-up studies of preterm infants are needed to determine how the consequences of early pain can be mitigated by appropriate analgesia.

\section{References}

Anand KJ, Coskun V, Thrivikraman KV, Nemeroff CB, Plotsky PM (1999) Long-term behavioral effects of repetitive pain in neonatal rat pups. Physiol Behav 66:627-637. CrossRef Medline

Anand KJ, Garg S, Rovnaghi CR, Narsinghani U, Bhutta AT, Hall RW (2007) Ketamine reduces the cell death following inflammatory pain in newborn rat brain. Pediatr Res 62:283-290. CrossRef Medline

Andrews K, Fitzgerald M (1994) The cutaneous withdrawal reflex in human neonates: sensitization, receptive fields, and the effects of contralateral stimulation. Pain 56:95-101. CrossRef Medline

Ashburner J, Hutton C, Frackowiak R, Johnsrude I, Price C, Friston K (1998) Identifying global anatomical differences: deformation-based morphometry. Hum Brain Mapp 6:348-357. CrossRef Medline

Avants BB, Epstein CL, Grossman M, Gee JC (2008) Symmetric diffeomorphic image registration with cross-correlation: evaluating automated labeling of elderly and neurodegenerative brain. Med Image Anal 12:2641. CrossRef Medline

Avants BB, Tustison NJ, Song G, Cook PA, Klein A, Gee JC (2011) A reproducible evaluation of ANTs similarity metric performance in brain image registration. Neuroimage 54:2033-2044. CrossRef Medline

Back SA, Miller SP (2014) Brain injury in premature neonates: a primary cerebral dysmaturation disorder? Ann Neurol 75:469-486. CrossRef Medline

Beggs S, Currie G, Salter MW, Fitzgerald M, Walker SM (2012) Priming of adult pain responses by neonatal pain experience: maintenance by central neuroimmune activity. Brain 135:404-417. CrossRef Medline

Boardman JP, Craven C, Valappil S, Counsell SJ, Dyet LE, Rueckert D, Aljabar P, Rutherford MA, Chew AT, Allsop JM, Cowan F, Edwards AD (2010) A common neonatal image phenotype predicts adverse neurodevelopmental outcome in children born preterm. Neuroimage 52:409-414. CrossRef Medline

Brummelte S, Grunau RE, Chau V, Poskitt KJ, Brant R, Vinall J, Gover A, Synnes AR, Miller SP (2012) Procedural pain and brain development in premature newborns. Ann Neurol 71:385-396. CrossRef Medline

Brummelte S, Chau CM, Cepeda IL, Degenhardt A, Weinberg J, Synnes AR, Grunau RE (2015) Cortisol levels in former preterm children at school age are predicted by neonatal procedural pain-related stress. Psychoneuroendocrinology 51:151-163. CrossRef Medline

Buskila D, Neumann L, Zmora E, Feldman M, Bolotin A, Press J (2003) Pain sensitivity in prematurely born adolescents. Arch Pediatr Adolesc Med 157:1079-1082. CrossRef Medline

Carbajal R, Rousset A, Danan C, Coquery S, Nolent P, Ducrocq S, Saizou C, Lapillonne A, Granier M, Durand P, Lenclen R, Coursol A, Hubert P, de Saint Blanquat L, Boëlle PY, Annequin D, Cimerman P, Anand KJ, Bréart G (2008) Epidemiology and treatment of painful procedures in neonates in intensive care units. JAMA 300:60-70. CrossRef Medline

Chakravarty MM, Steadman P, van Eede MC, Calcott RD, Gu V, Shaw P, Raznahan A, Collins DL, Lerch JP (2013) Performing label-fusion-based segmentation using multiple automatically generated templates. Hum Brain Mapp 34:2635-2654. CrossRef Medline

Chau V, Poskitt KJ, McFadden DE, Bowen-Roberts T, Synnes A, Brant R, Sargent MA, Soulikias W, Miller SP (2009) Effect of chorioamnionitis on brain development and injury in premature newborns. Ann Neurol 66:155-164. CrossRef Medline

Chau V, Synnes A, Grunau RE, Poskitt KJ, Brant R, Miller SP (2013) Abnormal brain maturation in preterm neonates associated with adverse developmental outcomes. Neurology 81:2082-2089. CrossRef Medline

Crair MC, Malenka RC (1995) A critical period for long-term potentiation at thalamocortical synapses. Nature 375:325-328. CrossRef Medline

Duerden EG, Foong J, Chau V, Branson H, Poskitt KJ, Grunau RE, Synnes A, Zwicker JG, Miller SP (2015) Tract-based spatial statistics in pretermborn neonates predicts cognitive and motor outcomes at 18 months. AJNR Am J Neuroradiol 36:1565-1571. CrossRef Medline

Duerden EG, Guo T, Dodbiba L, Chakravarty MM, Chau V, Poskitt KJ, Synnes A, Grunau RE, Miller SP (2016) Midazolam dose correlates with abnormal hippocampal growth and neurodevelopmental outcome in preterm infants. Ann Neurol 79:548-559. CrossRef Medline

Fitzgerald M (2005) The development of nociceptive circuits. Nat Rev Neurosci 6:507-520. CrossRef Medline

Fitzgerald M, Koltzenburg M (1986) The functional development of descending inhibitory pathways in the dorsolateral funiculus of the newborn rat spinal cord. Brain Res 389:261-270. Medline

Fitzgerald M, Walker SM (2009) Infant pain management: a developmental neurobiological approach. Nat Clin Pract Neurol 5:35-50. CrossRef Medline

Foilb AR, Lui P, Romeo RD (2011) The transformation of hormonal stress responses throughout puberty and adolescence. J Endocrinol 210:391398. CrossRef Medline

Genovese CR, Lazar NA, Nichols T (2002) Thresholding of statistical maps in functional neuroimaging using the false discovery rate. Neuroimage 15:870-878. CrossRef Medline

Goffaux P, Lafrenaye S, Morin M, Patural H, Demers G, Marchand S (2008) Preterm births: can neonatal pain alter the development of endogenous gating systems? Eur J Pain 12:945-951. CrossRef Medline

Goodman CS, Shatz CJ (1993) Developmental mechanisms that generate precise patterns of neuronal connectivity. Cell 72:77-98. CrossRef Medline

Grunau RE, Whitfield MF, Petrie-Thomas J, Synnes AR, Cepeda IL, Keidar A, Rogers M, Mackay M, Hubber-Richard P, Johannesen D (2009) Neonatal pain, parenting stress and interaction, in relation to cognitive and motor development at 8 and 18 months in preterm infants. Pain 143:138 146. CrossRef Medline

Grunau RE, Cepeda IL, Chau CM, Brummelte S, Weinberg J, Lavoie PM, Ladd M, Hirschfeld AF, Russell E, Koren G, Van Uum S, Brant R, Turvey SE (2013) Neonatal pain-related stress and NFKBIA genotype are associated with altered cortisol levels in preterm boys at school age. PLoS One 8:e73926. CrossRef Medline

Grunau RV, Whitfield MF, Petrie JH, Fryer EL (1994a) Early pain experience, child and family factors, as precursors of somatization: a prospective study of extremely premature and fullterm children. Pain 56:353-359. CrossRef Medline

Grunau RV, Whitfield MF, Petrie JH (1994b) Pain sensitivity and temperament in extremely low-birth-weight premature toddlers and preterm and full-term controls. Pain 58:341-346. CrossRef Medline

Guo T, Winterburn JL, Pipitone J, Duerden EG, Park MT, Chau V, Poskitt KJ, Grunau RE, Synnes A, Miller SP, Mallar Chakravarty M (2015) Automatic segmentation of the hippocampus for preterm neonates from early-inlife to term-equivalent age. Neuroimage Clin 9:176-193. CrossRef Medline

Guo T, Duerden EG, Adams E, Chau V, Branson HM, Chakravarty MM, Poskitt KJ, Synnes A, Grunau RE, Miller SP (2017) Quantitative assessment of white matter injury in preterm neonates: association with outcomes. Neurology 88:614-622. CrossRef Medline

Hathway GJ, Koch S, Low L, Fitzgerald M (2009) The changing balance of brainstem-spinal cord modulation of pain processing over the first weeks of rat postnatal life. J Physiol 587:2927-2935. CrossRef Medline

Hermann C, Hohmeister J, Demirakça S, Zohsel K, Flor H (2006) Longterm alteration of pain sensitivity in school-aged children with early pain experiences. Pain 125:278-285. CrossRef Medline

Jenkinson M, Smith S (2001) A global optimisation method for robust affine registration of brain images. Med Image Anal 5:143-156. CrossRef Medline

Jenkinson M, Bannister P, Brady M, Smith S (2002) Improved optimization for the robust and accurate linear registration and motion correction of brain images. Neuroimage 17:825-841. CrossRef Medline

Jenkinson M, Beckmann CF, Behrens TE, Woolrich MW, Smith SM (2012) Fsl. Neuroimage 62:782-790. CrossRef Medline

Klingmann PO, Kugler I, Steffke TS, Bellingrath S, Kudielka BM, Hellhammer DH (2008) Sex-specific prenatal programming: a risk for fibromyalgia? Ann N Y Acad Sci 1148:446-455. CrossRef Medline

Knaepen L, Patijn J, van Kleef M, Mulder M, Tibboel D, Joosten EA (2013) Neonatal repetitive needle pricking: plasticity of the spinal nociceptive circuit and extended postoperative pain in later life. Dev Neurobiol 73: 85-97. CrossRef Medline

Krishnan ML, Dyet LE, Boardman JP, Kapellou O, Allsop JM, Cowan F, Edwards AD, Rutherford MA, Counsell SJ (2007) Relationship between white matter apparent diffusion coefficients in preterm infants at termequivalent age and developmental outcome at 2 years. Pediatrics 120 : e604-609. CrossRef Medline

Laprairie JL, Murphy AZ (2009) Neonatal injury alters adult pain sensitivity 
by increasing opioid tone in the periaqueductal gray. Front Behav Neurosci 3:31. CrossRef Medline

Low LA, Schweinhardt P (2012) Early life adversity as a risk factor for fibromyalgia in later life. Pain Res Treat 2012:140832. CrossRef Medline

Malavolti AM, Chau V, Brown-Lum M, Poskitt KJ, Brant R, Synnes A, Grunau RE, Miller SP (2017) Association between corpus callosum development on magnetic resonance imaging and diffusion tensor imaging, and neurodevelopmental outcome in neonates born very preterm. Dev Med Child Neurol 59:433-440. CrossRef Medline

McCormick CM, Mathews IZ (2010) Adolescent development, hypothalamicpituitary-adrenal function, and programming of adult learning and memory. Prog Neuropsychopharmacol Biol Psychiatry 34:756-765. CrossRef Medline

Moss A, Alvares D, Meredith-Middleton J, Robinson M, Slater R, Hunt SP, Fitzgerald M (2005) Ephrin-A4 inhibits sensory neurite outgrowth and is regulated by neonatal skin wounding. Eur J Neurosci 22:2413-2421. CrossRef Medline

Ranger M, Chau CM, Garg A, Woodward TS, Beg MF, Bjornson B, Poskitt K, Fitzpatrick K, Synnes AR, Miller SP, Grunau RE (2013) Neonatal painrelated stress predicts cortical thickness at age 7 years in children born very preterm. PLoS One 8:e76702. CrossRef Medline

Ren K, Anseloni V, Zou SP, Wade EB, Novikova SI, Ennis M, Traub RJ, Gold MS, Dubner R, Lidow MS (2004) Characterization of basal and re-inflammation-associated long-term alteration in pain responsivity following short-lasting neonatal local inflammatory insult. Pain 110:588596. CrossRef Medline

Reynolds ML, Fitzgerald M (1995) Long-term sensory hyperinnervation following neonatal skin wounds. J Comp Neurol 358:487-498. CrossRef Medline

Ruda MA, Ling QD, Hohmann AG, Peng YB, Tachibana T (2000) Altered nociceptive neuronal circuits after neonatal peripheral inflammation. Science 289:628-631. CrossRef Medline

Schwaller F, Fitzgerald M (2014) The consequences of pain in early life: injury-induced plasticity in developing pain pathways. Eur J Neurosci 39:344-352. CrossRef Medline

Shatz CJ (1990) Impulse activity and the patterning of connections during CNS development. Neuron 5:745-756. CrossRef Medline

Smith GC, Gutovich J, Smyser C, Pineda R, Newnham C, Tjoeng TH, Vavasseur C, Wallendorf M, Neil J, Inder T (2011) Neonatal intensive care unit stress is associated with brain development in preterm infants. Ann Neurol 70:541-549. CrossRef Medline

Smith SM, Jenkinson M, Johansen-Berg H, Rueckert D, Nichols TE, Mackay CE, Watkins KE, Ciccarelli O, Cader MZ, Matthews PM, Behrens TE (2006) Tract-based spatial statistics: voxelwise analysis of multi-subject diffusion data. Neuroimage 31:1487-1505. CrossRef Medline

Sternberg WF, Scorr L, Smith LD, Ridgway CG, Stout M (2005) Long-term effects of neonatal surgery on adulthood pain behavior. Pain 113:347353. CrossRef Medline

Südmeyer M, Pieperhoff P, Ferrea S, Krause H, Groiss SJ, Elben S, Wojtecki L, Zilles K, Amunts K, Schnitzler A (2012) Longitudinal deformationbased morphometry reveals spatio-temporal dynamics of brain volume changes in patients with corticobasal syndrome. PLoS One 7:e41873. CrossRef Medline

Tam EW, Chau V, Ferriero DM, Barkovich AJ, Poskitt KJ, Studholme C, Fok ED, Grunau RE, Glidden DV, Miller SP (2011) Preterm cerebellar growth impairment after postnatal exposure to glucocorticoids. Sci Transl Med 3:105ra105. CrossRef Medline

Torsney C, Fitzgerald M (2003) Spinal dorsal horn cell receptive field size is increased in adult rats following neonatal hindpaw skin injury. J Physiol 550:255-261. CrossRef Medline

Vinall J, Miller SP, Bjornson BH, Fitzpatrick KP, Poskitt KJ, Brant R, Synnes AR, Cepeda IL, Grunau RE (2014) Invasive procedures in preterm children: brain and cognitive development at school age. Pediatrics 133:412421. CrossRef Medline

Walker SM, Franck LS, Fitzgerald M, Myles J, Stocks J, Marlow N (2009) Long-term impact of neonatal intensive care and surgery on somatosensory perception in children born extremely preterm. Pain 141:7987. CrossRef Medline

Zouikr I, Bartholomeusz MD, Hodgson DM (2016) Early life programming of pain: focus on neuroimmune to endocrine communication. J Transl Med 14:123. CrossRef Medline

Zwicker JG, Miller SP, Grunau RE, Chau V, Brant R, Studholme C, Liu M, Synnes A, Poskitt KJ, Stiver ML, Tam EW (2016) Smaller cerebellar growth and poorer neurodevelopmental outcomes in very preterm infants exposed to neonatal morphine. J Pediatr 172:81-87.e82. CrossRef Medline 